\title{
Inherited Thrombophilia in a Lebanese Family of Four Generations: A Case Report of Recurrent Miscarriage
}

This article was published in the following Dove Press journal: Vascular Health and Risk Management

\author{
Sara Khalife \\ Nisrine Bissar-Tadmouri \\ Department of Medical Laboratory \\ Technology, Faculty of Health Sciences, \\ Beirut Arab University, Tripoli, Lebanon
}

Introduction: Factor V Leiden (G1691A), prothrombin (G20210A) and MTHFR (C677T) gene mutations were investigated in many studies for their association with Deep Venous Thrombosis.

Case Presentation: A North Lebanese family has been examined, from an index case, a 40-year-old woman, who had a history of venous thrombosis with unexplained recurrent miscarriage. The index case was found to be heterozygous for factor V Leiden G1691A, prothrombin G20210A, and methylenetetrahydrofolate reductase C677T gene variants. Her family members were heterozygous for at least two of the three-point mutations, and multiple risk factors associated with thrombophilia were identified.

Conclusion: Our findings emphasize the need for clarifying the utility and futility of thrombophilia testing in the era of molecular diagnostics.

Keywords: factor V Leiden G1691A, MTHFR C677T, prothrombin G20210A, deep venous thrombosis, recurrent pregnancy loss, Lebanese family

\section{Introduction}

Thrombophilia is a hypercoagulable state that predisposes to thrombosis. It is manifested by inappropriate blood clot formation, a multifactorial condition that could arise from genetic, acquired factors or a combination of both. ${ }^{1}$ Thrombotic events are steadily recognized as an important source of morbidity and mortality. Among the inherited risk factors precipitating venous thromboembolism (VTE), are three main polymorphic biomarkers; prothrombin gene (FII G20210A), Factor $\mathrm{V}$ Leiden (FV G1691A) and methylenetetrahydrofolate reductase (MTHFR C677T), although the latter seems to be weakly associated with the condition. ${ }^{1}$

An increased risk of thrombosis has been observed in patients with multiple gene defects. Additionally, an increased risk of VTE has been seen in patients with co-occurrence of hereditary thrombophilias and/or prothrombotic polymorphisms. ${ }^{1}$

Despite the well-established positive correlation between inherited thrombophilia and thrombosis, inherited thrombophilia screening in asymptomatic persons is indicated exclusively for high-risk individuals that need to be promptly identified and tested. ${ }^{2}$

In this study we aim to examine the molecular profile of a thrombophilic Lebanese family for three thrombophilic mutations (FII 20210 GA, FV 1691 GA, and MTHFR $677 \mathrm{CT}$ ), to gain a better understanding of the relationship between the combinations of mutations and the clinical outcome on family members.
Correspondence: Sara Khalife

Department of Medical Laboratory

Technology, Faculty of Health Sciences,

Beirut Arab University, Tripoli, Lebanon

Tel +961 70557389

Email sara.khalifeh@bau.edu.lb 


\section{Case Presentation}

The study was approved by the Institutional Review Board at Beirut Arab University (IRB number: 2019H-0099-HS -R-0368). Written informed consent from patients and parental consent for minors were obtained for the case details to be published.

We describe a Lebanese family of four generations via patient II-5, a 40-year-old hypertensive woman who has a 5-year-old child and has experienced three consecutive pregnancy losses prior to 20 gestational weeks. She was then taking Oral contraceptive pills containing $3 \mathrm{mg}$ drospirenone and $0.03 \mathrm{mg}$ ethinylestradiol (Bayer HealthCare Pharmaceuticals, Yasmin, Whippany, Germany) for two years before her failed attempts to conceive. The history of our patient revealed one episode of deep venous thrombosis (DVT) at the age of thirty-seven, one year after she started the oral contraception. Her first-degree relatives were asymptomatic to the time of reporting except her brother (II3) who had an ischemic stroke at the age of 44.

The family comprised of 11 members, age ranging between 1 and 72 years, and the sex ratio was 1.2. Investigated risk factors include Hormonotherapy, underlying diseases, smoking habits, use of oral contraceptives, and family history of thromboembolic diseases (Table 1).
Three $\mathrm{mL}$ venous blood was collected from each patient in EDTA tubes. Plasma samples were then stored at $-20^{\circ} \mathrm{C}$ until assay. The mutations were detected by ThromboStrip- Opegen (Operon, Zaragoza, Spain) according to the manufacturer's protocol. The procedure consists of the following steps: DNA extraction, PCR amplification, strip hybridization, strip development, and detection.

Our index patient is a heterozygous carrier of FII G20210A, FV G1691A, and MTHFR C677T variants as shown by genetic analysis. The obtained results brought on the need to test all the patient's first-degree family members for the same mutations.

Each member of the investigated family has at least two out of the three mutations tested in this study (Figure 1).

In addition, most family members have different combinations of risk factors associated with thrombophilia, mainly hypercholesterolemia, smoking habits and use of oral contraceptives (Table 1).

\section{Discussion}

In this family, each investigated member has at least two prothrombotic gene variants out of the three tested, which

Table I Clinical Data of Study Participants

\begin{tabular}{|c|c|c|c|c|c|c|c|}
\hline $\begin{array}{l}\text { Pedigree } \\
\text { Code }\end{array}$ & $\begin{array}{l}\text { Age and } \\
\text { Gender }\end{array}$ & $\begin{array}{l}\text { Smoking } \\
\text { Habits }\end{array}$ & $\begin{array}{l}\text { Underlying } \\
\text { Diseases }\end{array}$ & $\begin{array}{l}\text { Pregnancy } \\
\text { Loss }\end{array}$ & $\begin{array}{l}\text { Use of Oral } \\
\text { Contraceptives }\end{array}$ & $\begin{array}{l}\text { Thrombotic } \\
\text { Episodes }\end{array}$ & $\begin{array}{l}\text { Surgery, Trauma or } \\
\text { Immobilization }\end{array}$ \\
\hline I I & $72 \mathrm{~F}$ & Active & Hypercholesterolemia & 2 & No & No & No \\
\hline III & $45 \mathrm{~F}$ & Active & None & 3 & $\begin{array}{l}\text { Ethinyl estradiol/ } \\
\text { drospirenone }\end{array}$ & No & IVF \\
\hline 112 & $52 M$ & Active & None & $N / A$ & $N / A$ & No & No \\
\hline 113 & $48 M$ & Active & Hypercholesterolemia & N/A & $\mathrm{N} / \mathrm{A}$ & $\begin{array}{l}\text { Ischemic } \\
\text { Stroke }\end{array}$ & $\begin{array}{l}\text { Mechanical } \\
\text { embolectomy }\end{array}$ \\
\hline 114 & $45 \mathrm{~F}$ & Active & None & 0 & No & No & No \\
\hline 115 & $40 \mathrm{~F}$ & Active & Hypercholesterolemia & 3 & $\begin{array}{l}\text { Ethinyl estradiol/ } \\
\text { drospirenone }\end{array}$ & DVT & No \\
\hline 116 & $45 M$ & Active & None & $N / A$ & $N / A$ & No & No \\
\hline IIII & $20 \mathrm{M}$ & Passive & None & $N / A$ & $N / A$ & No & No \\
\hline IIII2 & $23 \mathrm{~F}$ & Active & None & 0 & $\begin{array}{l}\text { Ethinyl estradiol/ } \\
\text { drospirenone }\end{array}$ & No & No \\
\hline III3 & $5 M$ & Active & None & $\mathrm{N} / \mathrm{A}$ & $\mathrm{N} / \mathrm{A}$ & No & No \\
\hline IV I & $I M$ & Passive & None & $\mathrm{N} / \mathrm{A}$ & $\mathrm{N} / \mathrm{A}$ & No & No \\
\hline
\end{tabular}

Abbreviations: DVT, Deep Venous Thrombosis; IVF, In-Vitro Fertilization; M, Male; F, Female; N/A, Not Applicable. 


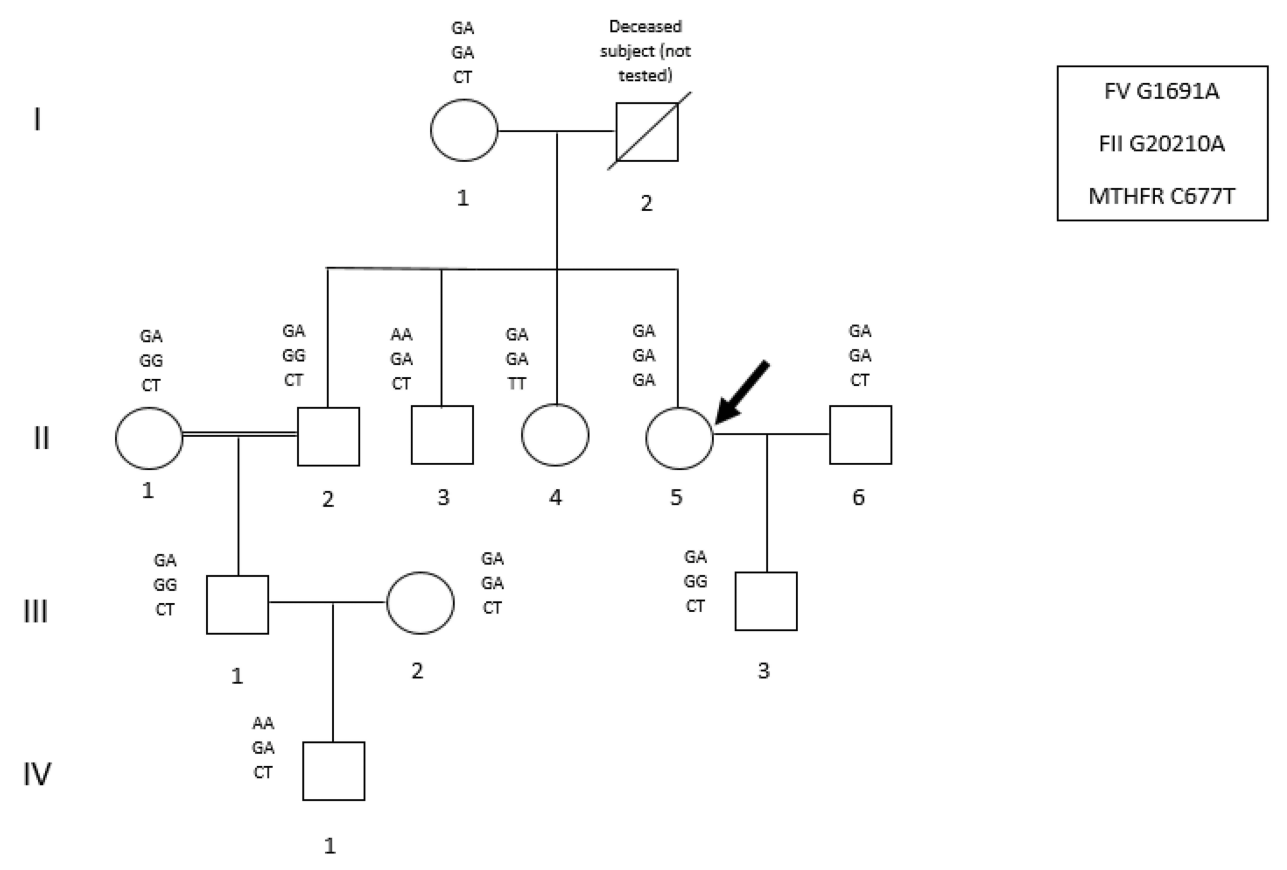

Figure I Pedigree of the investigated family with genotypes for the three selected gene variants. The propositus is indicated by an arrow.

can be considered as a clinical alarm due to zygosity status combined with the influence of environmental factors. A study on a large cohort of patients with VTE showed that both heterozygous and homozygous FV 1691A (FVL) carriers had a higher prevalence of isolated DVT compared to isolated pulmonary embolism (PE) or combined DVT/ PE clinical presentation. ${ }^{3}$ However, this same study revealed that double heterozygosity was not shown to significantly increase the prevalence of distal DVT or change its clinical presentation as compared to both heterozygous FVL and heterozygous FII 20210A carriers. ${ }^{3}$ A minor correlation was documented for MTHFR C677T and VTE unless additional risk factors are present. ${ }^{1}$

All tested individuals were either active or passive smokers, and $27.3 \%$ of the tested family members, including the index patient, were suffering from hypercholesterolemia. It was shown in earlier studies that both smoking and hypercholesterolemia are important risk factors for thrombosis. ${ }^{4,5}$

Thrombophilia has been recognized as a common cause of recurrent pregnancy loss (RPL). A meta-analysis showed an increased risk of VTE in pregnancy with FVL and FII G20210A carrier state. ${ }^{6}$ Consequently, women with unexplained early RPL should be targeted for FVL and FII G20210A testing, which are considered the most frequently requested genetic thrombophilia investigations. ${ }^{6}$ However, most experts and evidence-based guidelines argue against such measurements due to a lack of benefits. $^{2}$

Furthermore, the risk of thrombosis increased significantly in prothrombin G20210A and FV G1691A mutation carriers using combined hormonal contraceptives (CHCs) ${ }^{7,8}$

Altogether, FV G1691A and FII G20210A testing might identify individuals at risk of recurrent thrombotic episodes for targeted further intervention, but other data do not support this approach. ${ }^{2}$

Individual II-1 had recurrent in vitro fertilization failures on the 12th gestational week due to the occurrence of DVT in the fetus. Genetic testing revealed that she is a heterozygous carrier for both MTHFR C677T and FV G1691A mutations. However, the association between these anomalies and the repeated in vitro fertilization failures remains to be discussed as the evidence is inconclusive and not supported by cohort studies. Although, the European Society of Human Reproduction and Embryology and The Society of Obstetricians and Gynecologists of Canada recommend a risk assessment and genetic testing for thrombophilia to women undergoing assisted reproductive technology with ovarian stimulation so prophylaxis can be initiated, in many infertility centers in Lebanon, this is only done after repeated in vitro fertilization failures.

Our index patient had an episode of venous thromboembolism with RPL. Hence, molecular testing to detect 
genetic polymorphisms that predispose to thrombophilia is to be discussed as it provides information that can guide the therapeutic strategies and improve prognosis. It also allows proposing genetic testing and counseling to relatives to identify individuals at risk, since the natural history of this hereditary disease has an asymptomatic phase, which is sometimes very prolonged.

However, much uncertainty exists regarding the importance of genetic testing for thrombophilia, as management strategies are often based on the clinical history of the patient rather than on the underlying genetic anomaly.

Nevertheless, a common investigation technique has been adopted for the genetic testing of thrombophilia based on the detection of FV G1691A and FII G20210A mutations. $^{2}$

\section{Conclusion}

To our knowledge, this is the first study in Lebanon to describe a family with hereditary thrombophilia and examine several risk factors associated with this disease. In addition, we highlight the fact that thrombophilia testing in Lebanon is ordered inappropriately and is not adequately followed up. Education of physicians on the indications and the limitations of genetic tests, as well as genetic counselors are needed to assess each clinical condition and interpret the genetic and environmental risk factors. This will facilitate sound decision making regarding the test, and will help patients cope with the possible psychological distress.

\section{Acknowledgments}

We would like to thank the participants for their time and efforts in the present study

\section{Disclosure}

The authors declare no conflicts of interest in this work.

\section{References}

1. Simone B, De Stefano V, Leoncini E, et al. Risk of venous thromboembolism associated with single and combined effects of factor V Leiden, prothrombin 20210A and methylenetethraydrofolate reductase C677T: a meta-analysis involving over 11,000 cases and 21,000 controls. Eur J Epidemiol. 2013;28(8):621-647. doi:10.1007/s10654013-9825-8

2. Favaloro EJ. Genetic testing for thrombophilia-related genes: observations of testing patterns for factor V Leiden (G1691A) and prothrombin gene "Mutation" (G20210A). Semin Thromb Hemost. 2019;45 (7):730-742. doi:10.1055/s-0039-1694772

3. Campello E, Spiezia L, Dalla Valle F, Tormene D, Simioni P. Factor $\mathrm{V}$ Leiden paradox and the occurrence of distal vein thrombosis in a large cohort of thrombotic patients. Thromb Res. 2017;156:20-22. doi:10.1016/j.thromres.2017.05.025

4. Nielsen VG, Hafner DT, Steinbrenner EB. Tobacco smoke-induced hypercoagulation in human plasma: role of carbon monoxide. Blood Coagul Fibrinolysis. 2013;24:405-410. doi:10.1097/MBC.0b013e32 $835 \mathrm{~d} 5458$

5. Chan P, Tomlinsoin B, Tsai CW, Pan WH, Lee YS. Thrombophilia in patients with hypercholesterolemia. Metabolism. 1996;45:966-969.

6. Ziakas PD, Poulou LS, Pavlou M, Zintzaras E. Thrombophilia and venous thromboembolism in pregnancy: a meta-analysis of genetic risk. Eur J Obstet Gynecol Reprod Biol. 2015;191:106-111. doi:10.10 16/j.ejogrb.2015.06.005

7. Trenor CC, Chung RJ, Michleson AD, et al. Hormonal contraception and thrombotic risk: a multidisciplinary approach. Pediatrics. 2011; 127(2):347-357. doi:10.1542/peds.2010-2221

8. Momot AP, Nikolaeva MG, Yasafova NN, Zainulina MS, Momot KA, Taranenko IA. Clinical and laboratory manifestations of the prothrombin gene mutation in women of reproductive age. $J$ Blood Med. 2019;10:255-263. doi:10.2147/JBM.S212759
Vascular Health and Risk Management

\section{Publish your work in this journal}

Vascular Health and Risk Management is an international, peerreviewed journal of therapeutics and risk management, focusing on concise rapid reporting of clinical studies on the processes involved in the maintenance of vascular health; the monitoring, prevention and treatment of vascular disease and its sequelae; and the involvement of metabolic disorders, particularly diabetes. This journal is indexed on PubMed Central and MedLine. The manuscript management system is completely online and includes a very quick and fair peerreview system, which is all easy to use. Visit http://www.dovepress. com/testimonials.php to read real quotes from published authors. 